\title{
Comparison of methods to assess severity of common rust caused by Puccinia sorghi in maize
}

\author{
Cecilia Inés A. Bade \& Marcelo A. Carmona \\ Faculty of Agronomy, University of Buenos Aires, Buenos Aires, Argentina
}

Author for correspondence: Cecilia Bade, e-mail: cbade@agro.uba.ar

\begin{abstract}
Disease severity evaluation is an important decision support for adoption of strategies and tactics for disease control. The most commonly used method to assess disease severity is visual, but the problem is repeatability, due to subjectivity and imprecision of estimates. For Puccinia sorghi, a threshold of action of $1 \%$ severity was determined, so high precision is required in disease quantification. The aim of this study was to compare different assessment methods and analyze their association. Two diagrammatic scales were used to estimate severity, the Peterson and Amorim scales. Pustules were counted with the naked eye and with a 20x magnification hand lens. Software for disease quantification, Assess 2.0, was used to determine actual percentage area and lesion count. No significant differences were found between naked-eyed count and with magnifier. Lesion count with Assess 2.0 gave an imprecise result. Significant differences were found between diagrammatic scales. Compared with Assess 2.0, severity using Peterson was 2\% higher, showing widely scattered differences $\left(R^{2}=0.48\right)$. Overestimation with visual scales was suggested, especially at low severity levels. Counting pustules was more objective, precise and reproducible. Thus, a calibration curve was constructed $\left(\mathrm{R}^{2}=0.79\right)$, which will allow calculation of severity from counting pustules.
\end{abstract}

Key words: Zea mays, disease assessment methods, phytopathometry.

Common rust, caused by Puccinia sorghi, occurs in all areas of the world where maize is grown. In Argentina it is an important and endemic disease in the central region (Carmona et al., 2009). Evaluation of disease severity is an important decision support for adoption of strategies and tactics for disease control. The most commonly used method worldwide to assess disease severity is visual (Pataky \& Eastburn, 1993), generally assisted by diagrams such as the scale of Peterson et al. (1948). Diagrammatic scales are based on logarithmic grades, a concept developed by Horsfall \& Barrat (1945) based on Weber-Fechner's law, which says that visual acuity is proportional to the logarithm of the intensity of the stimulus. The problem of visual methods is repeatability, due to the subjectivity and imprecision of measures. Although numerous disease assessment keys, scales, computer training programs and rating systems have been developed to improve visual estimates, the accuracy and precision of these methodologies have rarely been evaluated and compared (Nutter \& Esker, 2006). Counting pustules would be more objective, but there are no studies that show a correlation between number of pustules and severity percentage in common maize rust that would allow both methods to be associated. There is only a study that showed correlation between foliar incidence and severity (Pataky \& Headrick, 1988). The objective of the present research was to compare different disease assessment methods in order to study their association.
Leaf samples of 60 plants of two commercial hybrids of Monsanto (DK670 and DK747) were collected at the end of March 2009, from a trial at the Faculty of Agronomy (UBA), which were at physiological maturity and naturally infected with P. sorghi. Three leaves were extracted per plant, the ear-1 leaf and the leaves immediately above and below it. Each leaf was cut in three and severity assessed for each third, using the scales of Peterson et al. (1948) and Amorim et al. (1987). Average per leaf was calculated. On the same samples, pustules were counted with the naked eye and with a 20x magnification hand lens, obtaining total pustules per leaf. Samples were scanned with a 75 dpi resolution and images analyzed with Assess 2.0, determining leaf lesion area percentage and lesion count. Methods were compared by pairs using regression analysis, complemented with Bland-Altman methodology (1986).

No significant differences were found between counting with the naked eye and with a magnifying glass. A linear relationship was obtained with $\mathrm{R}^{2}=0.99$, slope coefficient $b$ was $1.065(\mathrm{P}<0.0001)$ and the intercept $a 1.26$ $(\mathrm{P}=0.4783)$. Objectivity of the methods explains this result, as it reduces variability to counting errors, which were few even if the number of pustules was high.

Lesion count with Assess 2.0 was imprecise. A potential relationship between Assess 2.0 and naked-eyed count was obtained, with low correlation $\left(\mathrm{R}^{2}=0.49\right)$ and increasing differences as number of pustules rose. Except 
with low pustule number (0-50), the software usually underestimated lesion count. In common rust, pustules are heterogeneously distributed and usually concentrated in groups. The software counted groups of pustules as one lesion and often did not recognize them when they were isolated and small. Image analysis is based on color selection according to defined thresholds. Assess 2.0 frequently selected areas not corresponding to lesions, as shadows, ligula or parts of the midrib. Threshold levels were modified case by case to reduce these effects, but a subjectivity factor was introduced in this way. Image analysis with Assess has been successfully used in other diseases and other crops. Bock et al (2008) found that Assess was more precise than visual raters in citrus canker on grapefruit leaves. Angelotti et al. (2008) also used Assess to evaluate grapevine rust severity.

Severity assessed with both diagrammatic scales showed a linear relationship, with $\mathrm{R}^{2}=0.87$ (Figure 1). Less subjectivity in measures could explain the high coefficient of determination $\left(\mathrm{R}^{2}\right)$. Godoy et al. (2006) found that precision was higher in soybean rust if severity was assessed with the aid of diagrammatic scales. Estimations with Peterson's scale were higher than with Amorim's $(\mathrm{P}<0.0001)$. Average difference between both methods was $0.72 \%$. Differences could be related to the nature of the scales. Peterson's diagram was created to assess rust severity in wheat and barley, while Amorim's is used to evaluate rust in sugarcane. Shape and relative size of pustules are different and could have led to higher estimations with Peterson's diagram. Although Peterson's scale is of common use worldwide to assess $P$. sorghi in maize (Pataky \& Headrick, 1988; Dillard \& Seem, 1990; Pataky \& Eastburn, 1993) while Amorim's is not, comparing both methods proved that not only subjectivity influences estimation but also the scale used as reference. The homogeneous distribution of lesions on the diagrams added difficulty to the assessment, as $P$. sorghi has a very heterogeneous distribution on leaves. Considering a threshold of action of around 1\% severity (Carmona et al., 2009), high precision and accuracy is required in disease quantification, which is difficult to reach using diagrams.

Measuring with Assess 2.0 aimed to determine actual severity to be used as reference method. A potential curve fitted best between severity assessed with Peterson's diagram and with Assess $2.0\left(\mathrm{y}=0.4406 \mathrm{x}^{0.6211}\right)$. Estimates with Peterson's scale were on average $2 \%$ higher than with Assess $2.0(\mathrm{P}<0.0001)$ showing widely scattered differences $\left(\mathrm{R}^{2}=0.48\right)$ and increasing discrepancy as severity rose. Differences of this magnitude are very high and could lead to wrong conclusions. But the software was imprecise in selecting damaged area, so real severity could not be determined. Although resolution of images was low, Nutter et al. (1993) already stated that image analysis to determine true levels of disease may not always be as objective as was once thought.

Indeed, overestimation using visual scales is also possible. Forbes and Jeger (1987) found that worst overestimation errors with visual scales occurred when severity was under $25 \%$. Parker et al. (1995) compared estimated and actual severity in Blumeria graminis and Septoria tritici in wheat and concluded that estimations were imprecise and overestimations occurred mainly under $10 \%$ severity. As most of the estimations in this trial were under $10 \%$, overestimation with diagrams is probable. On the other hand, several authors have concluded that percentage area estimations do not obey Weber-Fechner's law, as supposed by Horsfall and Barrat (Philip 1947; Stevens \& Galanter 1957; Baird \& Noma 1978; Hebert, 1982). Baird \& Noma (1978) proposed four different stimulus-response curves: linear, logarithmic (Weber-Fechner's law, with frequent deviations on extreme portions of the curve), exponential and potential (also called Steven's law and verified in many experiments, including visual area estimations). In this study, severity seemed to be a power function of number of pustules, confirming Steven's law (Figure 2).

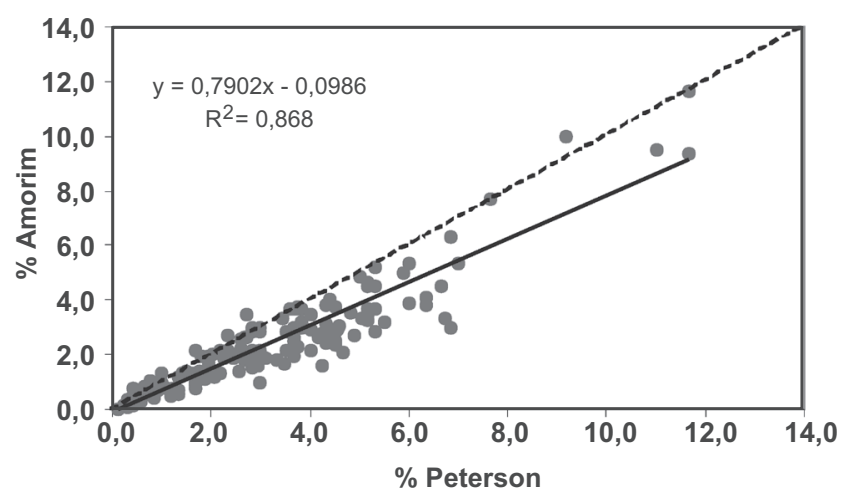

FIGURE 1 - Linear relationship between severity percentage of Puccinia sorghi per leaf estimated visually in maize with the aid of two diagrammatic scales, Peterson et al. (1948) and Amorim et al. (1987).

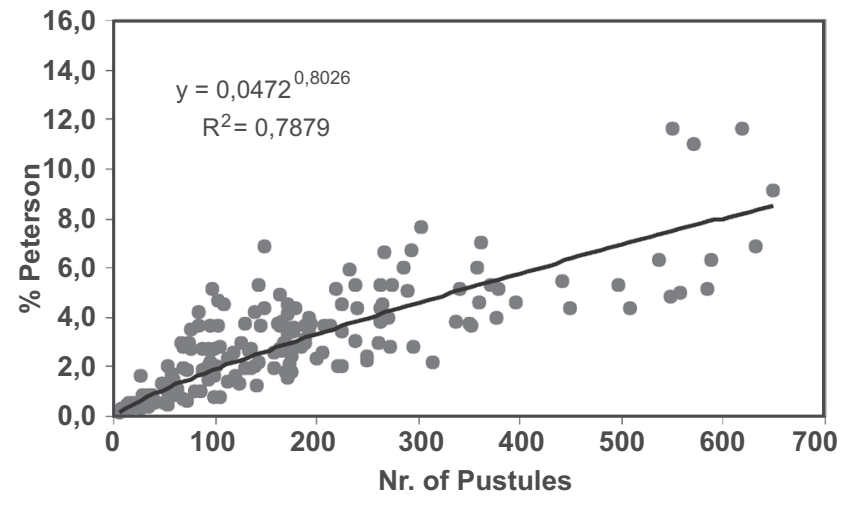

FIGURE 2 - Power function associating number of pustules of Puccinia sorghi per leaf counted with the naked eye and severity percentage assessed with Peterson's diagram in maize. 
Regression between severity percentage estimated with Peterson's scale and number of pustules counted with the naked eye showed a potential relationship with $\mathrm{R}^{2}=0.79$ (Figure 2). Causes of variability include subjectivity of the rater, difficulties mentioned when using diagrams, different sizes of leaves and pustules and type of hybrid.

Concluding, pustule count is a more objective, precise and reproducible method than visual estimations. A calibration curve was determined between number of pustules and severity, with significant adjustment. For people not trained in disease quantification it will be easier and more accurate to count pustules and calculate severity using the model. A threshold of action of around $1 \%$ severity corresponds, according to the model, to 45 pustules on average per leaf. This magnitude can be easily counted. However, leaves with 100 pustules can show $1-6 \%$ disease severity (Figure 2). Considering a threshold of $1 \%$, it was proved that it is difficult to have that precision in a visual estimation. It would be more accurate to find the threshold of action in number of pustules instead of severity in the future.

\section{REFERENCES}

Amorim L, Bergamin-Filho A, Sanguino A, Cardoso C, Moraes VA, Fernandes CR (1987) Metodologia de avaliação da ferrugem da cana-de-açúcar (Puccinia melanocephala). Boletim Técnico Copersucar 39:13-16.

Angelotti F, Scapin C, Tessmann DJ, Vida JB, Oliveira RR, Canteri MG (2008) Diagrammatic scale for assessment of grapevine rust. Tropical Plant Pathology 33:439-443.

Baird JC, Noma EJ (1978) Fundamentals of scaling and psychophysics. New York NY. John Wiley and Sons.

Bland JM, Altman DG (1986) Statistical methods for assessing agreement between two methods of clinical measurement. Lancet 1:307-310.

Bock CH, Parker PE, Cook AZ, Gottwald TR (2008) Visual rating and the use of image analysis for assessing different symptoms of citrus canker on grapefruit leaves. Plant Disease 92:530-541.
Dillard HR, Seem RG (1990) Use of an action threshold for common maize rust to reduce crop loss in sweet corn. Phytopathology 80:846-849.

Carmona M, Quiroga M, Diaz C, Fernandez P, Sautua F (2009) Control químico de la roya común del maíz (Puccinia sorghi): Criterio basado en el Umbral de Daño Económico (UDE). Tropical Plant Pathology 34:S120.

Forbes GA, Jeger MJ (1987) Factors affecting the estimation of disease intensity in simulated plant structures. Zeitschrift für Pflanzenkrankheiten und Pflanzenschutz 94:113-120.

Godoy CV, Koga LJ, Canteri MG (2006) Diagrammatic scale for assessment of soybean rust severity. Fitopatologia Brasileira 31:63-68.

Hebert TT (1982) The Rationale for the Horsfall-Barratt Plant Disease Assessment Scale. Phytopathology 72:1269.

Horsfall JG, Barratt RW (1945) An Improved Grading System for Measuring Plant Disease. Phytopathology 35:655.

Nutter FW, Gleason ML, Jenco JH, Christians NC (1993) Assessing the accuracy, intra-rater repeatability, and inter-rater reliability of disease assessment systems. Phytopathology 83:806-812.

Nutter FW, Esker PD (2006) The role of psychophysics in phytopathology: The Weber-Fechner law revisited. European Journal of Plant Pathology 114:199-213.

Parker SR, Shaw MW, Royle DJ (1995) The reliability of visual estimates of disease severity on cereal leaves. Plant Pathology 44:856-864.

Pataky JK, Eastburn DM (1993) Comparing partial resistance to Puccinia sorghi and applications of fungicides for controlling common rust on sweet corn. Phytopathology 83:1046-1051.

Pataky JK, Headrick JM (1988) Relationships between common rust incidence and severity on a susceptible and a partially resistant sweet corn hybrid. Phytopathology 78:1155-1160.

Peterson RF, Campbell AB, Hannah AE (1948) A diagrammatic scale for estimating rust intensity on leaves and stems of cereals. Canadian Journal of Research 26: 496-500

Philip BR (1947) The relationship of speed and exposure time in a perceptual task. Journal of Experimental Psychology 37:178-186.

Stevens SS, Galanter EH (1957) Ratio scales and category scales for a dozen perceptual continua. Journal of Experimental Psychology 54:377-411.

TPP 83 - Received 1 March 2010 - Accepted 6 July 2011 Section Editor: Lilian Amorim 